\title{
ESTRATÉGIAS DE MARKETING VERDE NA COMERCIALIZAÇÃO DE PRODUTOS ORGÂNICOS ${ }^{1}$
}

\author{
Carolina Obregão da Rosa ${ }^{2}$ \\ Victor Fraile Sordi ${ }^{3}$ \\ Rodrigo Garóffalo Garcia ${ }^{4}$ \\ Clandio Favarini Ruviaro 5
}

Resumo: As estratégias de marketing verde tentam atribuir maior valor aos produtos, destacando seus aspectos relacionados à preservação do meio ambiente e à sustentabilidade. $\mathrm{O}$ presente estudo procurou verificar se a aplicação de estratégias de marketing verde na comercialização de produtos orgânicos agrega, na percepção do consumidor, maior valor aos produtos alimentícios. $\mathrm{O}$ estudo foi desenvolvido em três etapas com natureza e caráter metodológicos distintos, em que se procurou identificar a disposição dos consumidores a pagar mais por produtos orgânicos, compreender os motivos pelos quais há ou não esta disposição e discutir as estratégias utilizadas na comercialização destes produtos. Os resultados mostram que as estratégias de marketing verde aplicadas na comercialização de produtos orgânicos realmente criam maior valor na concepção de boa parte dos consumidores e que uma parcela considerável deles mostra disposição para pagar um valor adicional para consumir tais produtos. Entretanto, muitos destes consumidores não têm uma real noção do que seja um produto orgânico e seus benefícios, sendo que, nesses casos, estratégias mais efetivas de comunicação de valor são necessárias.

Palavras-chave: Consumo Verde, Valor Agregado, Alimentos, Diferenciação.

1 Recebido em: 10/02/2014; Aceito em: 10/04/2014.

2 Mestranda em Agronegócios pela Universidade Federal da Grande Dourados (UFGD). E-mail: carolinarosa@ ufgd.edu.br.

3 Mestrando em Agronegócios pela Universidade Federal da Grande Dourados (UFGD). E-mail: victor.sordi@ yahoo.com.br

4 Doutor em Zootecnia, Professor Titular da Universidade Federal da Grande Dourados (UFGD). E-mail: rodrigogarcia@ufgd.edu.br

5 Doutor em Agronegócios, Professor Titular da Universidade Federal da Grande Dourados (UFGD). E-mail: clandioruviaro@ufgd.edu.br. 


\begin{abstract}
The green marketing strategies attempt to assign greater value to products highlighting their aspects related to preservation of the environment and sustainability. The present study sought to verify whether the application of the green marketing strategies in the marketing of organic products aggregates, in consumer perception, greater value to food products. The study was conducted in three stages with distinct methodological nature and character, in which it sought to identify the provision of consumers to pay more for organic products, understand the reasons why there is or is not available and discuss the strategies used in the marketing of these products. The results demonstrated that the green marketing strategies applied on the marketing of organic products really created greater value in the design of a good part of the consumers, and that a considerable portion of them, demonstrates willingness to pay an additional amount to consume such products. However, many of these consumers don't have a real concept of what is an organic product, what are the benefits, and in these cases, more effective strategies for communicating value are required.
\end{abstract}

Key-words: Green consumption, Value added, Food, Differentiation.

\title{
1. Introdução
}

Há uma mudança significativa no perfil dos consumidores de produtos oriundos do agronegócio, sobretudo, quando se trata do consumo de alimentos (NEVES et al., 2007; NEVES, 2011; VERAIN, 2012). Os consumidores preocupados com a saúde e conscientes das necessidades de maior responsabilidade socioambiental das organizações exigem dessas empresas uma postura ética e responsável para com a sociedade e a natureza (JANSSON et al., 2010; YOUNG et al., 2010). Nesse sentido, procuram produtos mais saudáveis, que minimizem as agressões ao meio ambiente e sejam éticos com as pessoas envolvidas tanto na produção como no consumo, consequentemente, procuram por produtos e empresas mais sustentáveis (BALDWIN, 2012; KOTLER; KARTAJAYA, 2010).

Essa demanda por produtos considerados mais sustentáveis, com impacto ambiental e social reduzido, ou seja, concebidos como menos prejudiciais ao meio ambiente e à saúde humana, tanto em seu conteúdo quanto em sua embalagem, é considerada uma demanda por produtos verdes. Para se adequar a essas novas demandas de consumo e às exigências dos 
consumidores sociorresponsáveis, as empresas procuram adequar seus produtos e elaborar estratégias de marketing para alcançar esse "novo mercado consumidor", aliando o conceito de produtos mais verdes às marcas, no intuito de criar maior valor e almejar maior lucratividade (DARNALL et al., 2012; KOTLER; KARTAJAYA, 2010; OTTMAN et al., 2006; YOUNG et al., 2010).

Com a finalidade de criar maior valor e satisfazer a demanda por produtos mais verdes, foi criada no mundo dos negócios a terminologia "marketing verde", em que, de acordo com Ottman (2013), se usam ferramentas mercadológicas que visam a criar e a disponibilizar no mercado produtos social e ambientalmente responsáveis. O termo marketing verde é utilizado também para descrever as estratégias que os profissionais de marketing procuram utilizar objetivando a satisfação do consumidor envolvido com as questões ambientais e sociais (AGRAWAL, 2013; OTTMAN et al., 2006; PEATTIE; CRANE, 2005).

Essas estratégias atribuem maior valor aos produtos por meio de mecanismos como a rastreabilidade, certificações, garantindo atributos e ressaltando informações consideradas "verdes", como embalagens biodegradáveis, desperdícios minimizados na produção e no consumo, uso de materiais reciclados, baixa emissão de carbono, preço justo ao produtor, composição nutricional adequada, entre outros aspectos "verdes" que possam valorizar os produtos (AGRAWAL, 2013; CRONIN, 2011; GINSBERG; BLOOM, 2004; MATHUR; MATHUR, 2000; PEATTIE; CRANE, 2005).

Outras dimensões do marketing tradicional também são contempladas pelas estratégias de marketing verde, tais como: a preocupação com a melhor maneira de distribuir e disponibilizar os produtos com o mínimo uso de recursos e com a utilização de análises dos ciclos de vida e da logística reversa; a comunicação e a promoção com incentivos ao consumo sustentável, ao viés ecológico dos produtos e à necessidade de se ter um planeta mais sustentável, entre outras infinidades de propostas que ressaltam as qualidades entendidas como favoráveis ao consumo 
de produtos verdes (CRONIN, 2011; GINSBERG; BLOOM, 2004; OTTMAN, 2013).

Nesse contexto, os alimentos orgânicos, ou seja, conforme Winter e Davis (2006), os produtos alimentícios cultivados sem agrotóxicos e sem fertilizantes químicos, provenientes de sistemas agrícolas baseados em processos naturais que minimizam os impactos ambientais e a perda de biodiversidade mantendo um uso sustentável do solo, podem se diferenciar dos produtos convencionais, satisfazendo a demanda por produtos mais sustentáveis e utilizando as estratégias de marketing verde (HUGHNER, 2007; OTTMAN, 2013; SHEPHERD et al., 2005).

No entanto, para que essas estratégias de marketing verde sejam efetivadas, seja com produtos orgânicos ou não orgânicos, os custos relacionados aos atributos verdes dos produtos devem ser absorvidos pelas empresas e pelos consumidores; e os últimos devem estar dispostos a pagar mais para consumir esse tipo de produto (NEVES, 2007; SHEPHERD et al., 2005;WOOLVERTON; DIMITRI, 2010).

Destarte, este estudo pretende verificar se a aplicação de estratégias de marketing verde na comercialização de produtos orgânicos agrega, na percepção do consumidor, maior valor aos produtos alimentícios e, para tanto, consultar se esses consumidores estão dispostos a pagar um valor maior para adquirir produtos orgânicos.

\section{O comportamento do consumidor e as estratégias de marketing verde}

O comportamento do consumidor trata do estudo sistemático dos processos de compra e troca envolvidos na aquisição, consumo, avaliação e descarte de produtos, serviços, ideias e experiências (MOWEN; MINOR, 2003). Neste sentido, com a perspectiva de prever comportamentos futuros dos consumidores e simplificar uma realidade 
complexa, muitos modelos de comportamento do consumidor foram criados (LOPES; DA SILVA, 2012).

Um destes modelos integradores é o de Blackwell et al. (2005), que permite a distinção e a compreensão das diferentes fases do processo decisório de compra. Para esses autores, o processo decisório de compra é dividido em etapas: (a) Reconhecimento da Necessidade, (b) Busca, (c) Avaliação de Alternativa Pré-Compra, (d) Compra, (e) Consumo e (f) Avaliação Pós-Consumo.

Desta maneira, as estratégias de marketing verde podem influenciar todas estas etapas do processo de decisão de compra sugeridas por Blackwell et al. (2005): (a) conscientizando o consumidor dos benefícios dos "produtos verdes" e ajudando-o a reconhecer as necessidades de consumo deste tipo específico de produto (AGRAWAL, 2013; BLACKWELL et al., 2005; CRONIN, 2011; GINSBERG; BLOOM, 2004); (b) fornecendo informações aos consumidores, facilitando e influenciando seu processo de busca e sua escolha futura (AGRAWAL, 2013; BLACKWELL et al., 2005; MOWEN; MINOR, 2003; OTTMAN et al., 2006); (c) e (d) explicitando os benefícios "verdes" do produto, sugerindo maior valor em decorrência dos atributos relativos à sustentabilidade em comparação às demais opções de compra e disponibilizando o produto de maneira atrativa e adequada ao perfil dos "consumidores verdes" (AGRAWAL, 2013; BLACKWELL et al., 2005; MOWEN; MINOR, 2003; PEATTIE; CRANE, 2005); (e) e (f) disponibilizando um produto com qualidade esperada, mantendo a preocupação com a experiência de compra e consumo do consumidor desde o uso até o descarte do produto, evidenciando os benefícios "verdes" de todo o processo (AGRAWAL, 2013; BLACKWELL et al., 2005; CRONIN, 2011; GINSBERG; BLOOM, 2004).

Neste sentido, Tarkiainen e Sundqvist (2005) sugerem que a compra de produtos orgânicos, produtos que são o foco da presente pesquisa, também pode ser influenciada e prevista pelo fato de geralmente se tratar de uma decisão moral que reflete a utilidade coletiva de bem-estar ambiental e, 
também, de certa forma, uma decisão de bem-estar individual. Neste caso, é possível prever o comportamento de compra dos consumidores de alimentos orgânicos pela intenção de comprar alimentos orgânicos.

Os dados revelados por Smith et al. (2009) destacam aumento crescente nas intenções de compra de produtos orgânicos e sugerem que as estratégias de marketing direto podem ajudar a maximizar tais intenções. Em contrapartida, Tarkiainen e Sundqvist (2005) apontam os preços e a falta de disponibilidade dos produtos orgânicos como problemas para a expansão dessas intenções de compra.

As estratégias de marketing verde podem influenciar no processo decisório de compra (AGRAWAL, 2013; BLACKWELL et al., 2005; MOWEN; MINOR, 2003; OTTMAN et al., 2006). Há evidências de que o comportamento de compra de produtos orgânicos pode ser previsto e também influenciado por normas subjetivas de utilidade coletiva (TARKIAINEN; SUNDQVIST, 2005) e que há uma tendência de maior conscientização e aumento nas intenções de compra de produtos orgânicos (SMITH et al., 2009), sendo que um dos problemas enfrentados pelo mercado de produtos orgânicos é o maior preço destes produtos. Assim, evidencia-se a necessidade de identificar se as estratégias de marketing verde podem agregar maior valor aos produtos orgânicos na visão dos consumidores para que eles se interessem em pagar um preço maior por esses produtos em relação aos produtos convencionais.

\section{Metodologia}

Com o intuito de alcançar o objetivo proposto, este trabalho foi desenvolvido em três etapas, nas quais o sujeito da pesquisa foi a população do estado de Mato Grosso do Sul, potenciais consumidores de produtos orgânicos, e também uma empresa brasileira do setor orgânico que oferece o produto foco do estudo, no caso, ovos orgânicos. O ovo orgânico foi escolhido justamente pelo caráter complexo quanto à sua diferenciação em relação aos ovos convencionais. Toda a metodologia 
foi guiada pelo aparato teórico pesquisado, na tentativa de se aprofundar na discussão central da pesquisa, no caso as estratégias de marketing verde, e sua utilização com produtos orgânicos. A seguir, serão descritas as etapas e seus objetivos.

\subsection{Primeira etapa da metodologia: Survey}

A primeira etapa consistiu de um estudo descritivo-estatístico por meio de um levantamento de campo, ou survey, em uma amostra da população. Estipulou-se o mínimo de 400 entrevistados, determinado por cálculo a partir de erro máximo de $5,0 \%, 95,5 \%$ de confiança $(\mathrm{k}=2)$, e princípio máximo de indeterminação $(\mathrm{p}=\mathrm{q}=50 \%)$.

O questionário (Anexo 1) foi composto por perguntas objetivas do tipo fechado. A aplicação do questionário ocorreu durante o mês de novembro de 2013, tendo sido editado em um formulário do Google Drive ${ }^{\circledR}$ e disponibilizado on-line. Sua divulgação ocorreu nas redes sociais por vários agentes em todo o estado. Os dados coletados foram analisados por meio de estatística descritiva e de coeficientes de correlação de Pearson ( $r$ de Pearson). A correlação é uma medida de associação bivariada do grau de relação linear entre duas variáveis quantitativas (GARSON, 2009). As variáveis consideradas para cálculo dos coeficientes foram sexo, idade, escolaridade, estado civil e renda. Tais variáveis são comumente utilizadas em pesquisas de marketing para caracterizar um determinado mercado consumidor (MALHOTRA, 2006).

Os resultados obtidos nesta etapa serviram de referência para a realização da segunda etapa do método utilizado. A seguir, são apresentados os dados referentes ao perfil da amostra utilizada na primeira etapa. 


\subsubsection{Perfil da amostra}

A amostra inicial foi composta por $57 \%$ de entrevistadas mulheres e $43 \%$ de homens. Entre os participantes, $2 \%$ têm ensino fundamental completo; $5 \%$, ensino médio incompleto; $10 \%$, ensino médio completo; $26 \%$, ensino superior incompleto; e $57 \%$, ensino superior completo. A maior parte dos participantes é casada (49\%), seguida de solteiros (39\%), divorciados (5\%), viúvos (3\%) e pessoas sem estado civil definido $(3 \%)$.

Com base na renda familiar ${ }^{6}$, a pesquisa apresentou o seguinte perfil amostral: $2 \%$ dos entrevistados declararam ter rendimento familiar correspondente ao estrato 1 - com renda até $\mathrm{R} \$ 854,00 ; 6 \%$ declararam obter renda correspondente ao estrato 2 - de $\mathrm{R} \$ 854,00$ a $\mathrm{R} \$ 1.113,00 ; 5 \%$ encontram-se no estrato 3 - de R $\$ 1.113,00$ a 1.484,00; $15 \%$ correspondem ao estrato 4 - de $\mathrm{R} \$ 1.484,00$ a $\mathrm{R} \$ 2.674,00 ; 25 \%$ correspondem ao estrato 5 - de R $\$ 2.674,00$ a $\mathrm{R} \$ 4.681,00 ; 32 \%$ correspondem ao estrato 6 - de $\mathrm{R} \$ 4.681,00$ a $\mathrm{R} \$ 9.867,00 ; 12 \%$ correspondem ao estrato 7 - de $\mathrm{R} \$$ 9.867,00 a R\$ 17.434,00; e 2\% obtêm renda acima de $\mathrm{R} \$ 17.434,00$.

Quanto às profissões dos entrevistados, o perfil é heterogêneo. Participaram da pesquisa vários tipos de profissionais: da saúde, das ciências agrárias, da educação, da administração de empresas, do serviço público, do comércio, da publicidade, da tecnologia da informação, profissionais autônomos, domésticas, donas de casa, estudantes, entre outros.

\subsection{Segunda etapa da metodologia: Entrevistas qualitativas}

A segunda etapa da pesquisa consistiu em entrevistas semiestruturadas com 10 dos participantes da primeira etapa, objetivando o aprofundamento das questões resultantes das análises da fase anterior a respeito da propensão dos entrevistados a pagar ou não pagar mais por um produto

6 Como critério de renda foi utilizado os estratos sociais de Kamakura e Mazzon (2013), a qual influenciou a alteração do Critério Brasil a partir de 2015. 
orgânico e esclarecer se, na opinião deles, os produtos orgânicos oferecem maior valor agregado.

Os entrevistados foram selecionados primeiramente pelas respostas dadas no questionário da primeira etapa, com o intuito de se manter a mesma proporção encontrada nas respostas quanto à sua disposição em aceitar ou não maior preço para adquirir um produto orgânico e, posteriormente, pela acessibilidade e disponibilidade em responder à pesquisa no período estipulado. As entrevistas foram feitas pessoalmente, com transcrição simultânea das respostas.

Foram entrevistados três indivíduos, que responderam "Sim" na etapa 1, ou seja, estariam dispostos a pagar mais por um produto orgânico (no caso da pesquisa em questão o ovo orgânico); três indivíduos, que responderam "Não", ou seja, não estariam dispostos a pagar mais pelo produto orgânico: outros quatro respondentes que não responderam nem "Sim" nem "Não", sendo que três indivíduos responderam "Não terem opinião formada" e um indivíduo respondeu "Outro", ou seja, necessita de outras informações para a decisão de comprar ou não produtos orgânicos por um preço superior. Posteriormente, para complementar a discussão proposta, partiu-se para a terceira etapa do método abordado.

\subsection{Terceira etapa da metodologia: Estudo de caso}

A terceira etapa incidiu no estudo das estratégias de comercialização adotadas por uma empresa, que, por motivos éticos, será referida como "Produtos Orgânicos LTDA.", que comercializa seis produtos orgânicos distintos para várias regiões do país, entre os quais o ovo orgânico.

Os contatos com a empresa foram feitos com um dos sócios através de correio eletrônico (e-mail). Foram usadas nas análises informações disponíveis no site da empresa e nas embalagens dos produtos, além das informações disponibilizadas pela empresa nas entrevistas. 
Buscou-se identificar, entre as estratégias de comercialização adotadas pela empresa, as estratégias de marketing verde discutidas pela bibliografia utilizada no estudo, comparando as diretrizes que emergem das respostas dos consumidores entrevistados nas etapas anteriores da metodologia com as estratégias utilizadas pela empresa. Após as três etapas, os dados foram organizados e discutidos conforme exposto no tópico a seguir.

\section{Resultados e discussão}

4.1. Disposição dos consumidores a pagar mais pelo produto orgânico

$\mathrm{Na}$ pesquisa quantitativa, verificou-se que 34\% dos consumidores aceitariam pagar um valor adicional para consumir ovos orgânicos, enquanto $33 \%$ não aceitariam e outros $31 \%$ não têm uma opinião formada sobre esta questão. Os outros $2 \%$ correspondem às respostas que não se encaixaram em nenhuma das três opções anteriores (Figura 1).

Considerando os $31 \%$ de consumidores que não têm uma opinião formada se pagariam ou não a mais para consumir ovos orgânicos, mais os $2 \%$ de outras respostas, que, de certa forma, também indicam falta de opinião formada devida ao desconhecimento sobre este tipo de produto, observase uma proporção semelhante entre os consumidores que aceitam, os que não aceitam e os que não têm uma opinião formada. Estes dados indicam que há uma parcela considerável de consumidores em que o marketing verde pode ser mais bem explorado, se utilizadas as estratégias corretas. 


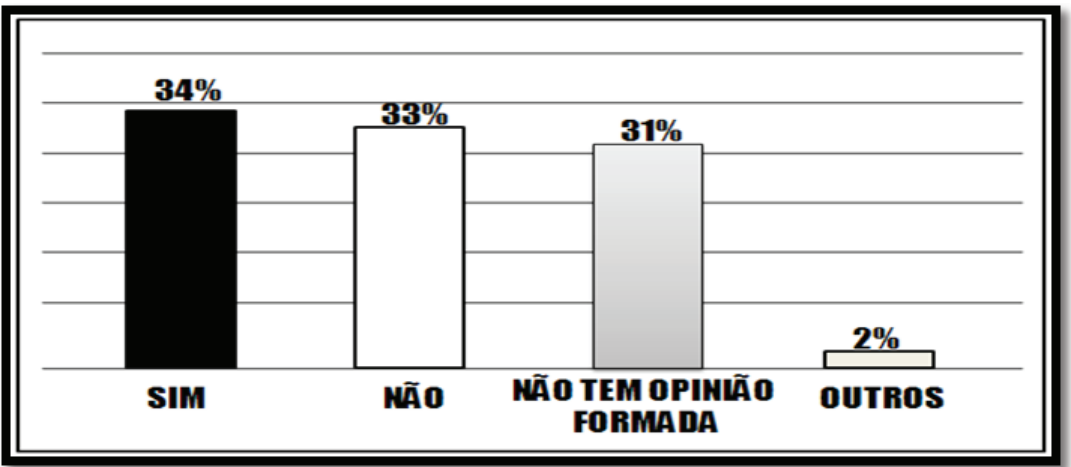

Figura 1 - Disposição dos consumidores a pagar mais pelo produto orgânico

Daqueles consumidores que aceitariam pagar mais para consumir ovos orgânicos, a maioria significativa (73\%) aceita pagar no máximo $10 \%$ a mais por uma dúzia de ovos orgânicos (Figura 2). Tal dado indica que, apesar de os consumidores visualizarem um valor superior no produto orgânico, eles não estão dispostos a desembolsar grandes acréscimos percentuais relativos ao preço do produto convencional.

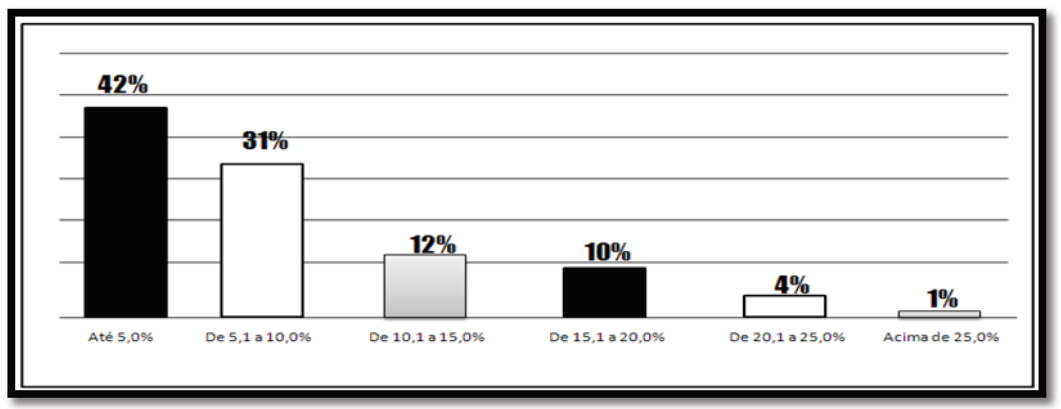

Figura 2 - Quanto de acréscimo nos preços os consumidores estão dispostos a pagar 
Confirma-se a necessidade de comunicação mais efetiva, através de ferramentas mercadológicas para produtos de maior valor agregado (KOTLER; ARMSTRONG, 2007), como no caso de as organizações produtoras de produtos orgânicos optarem por estratégias de diferenciação com maior preço. Se uma dúzia de ovos comuns tradicionais está sendo comercializada ao preço hipotético de 10 unidades monetárias segundo os dados expostos, uma parcela substancial dos consumidores estaria disposta a pagar somente 11 unidades monetárias num produto orgânico de maior valor agregado e, provavelmente, com maior custo a ser absorvido. Na Figura 3, pode-se visualizar esta disposição de compra pelas faixas de renda.

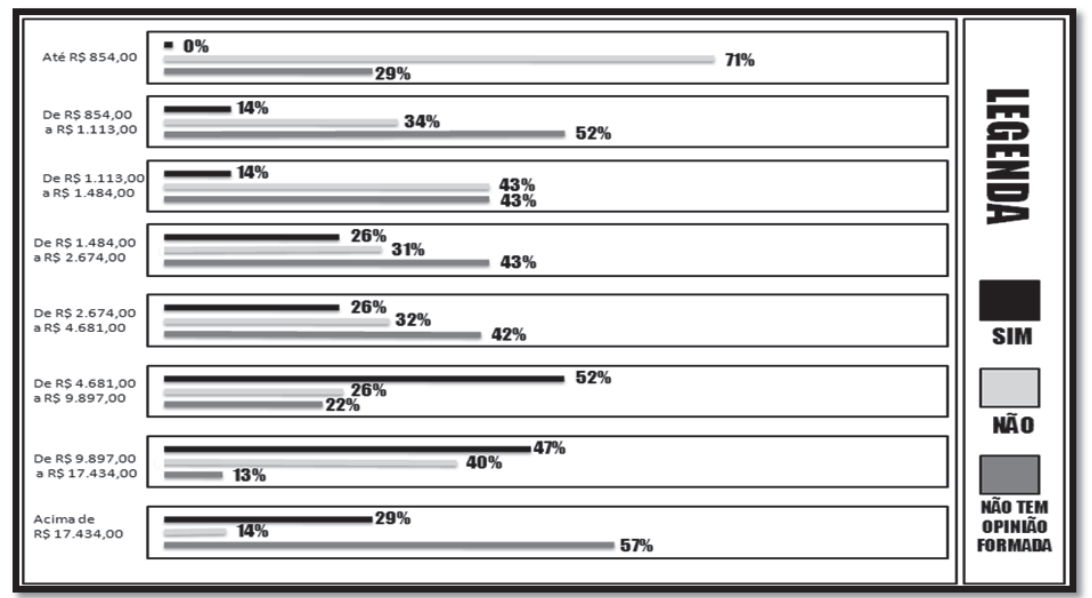

Figura 3 - Disposição a pagar mais pelo produto orgânico conforme a renda familiar

Observa-se também uma disposição crescente para pagar um acréscimo no preço de ovos orgânicos até o estrato socioeconômico 6 (renda familiar entre $\mathrm{R} \$ 4.681,00$ a $\mathrm{R} \$$ 9.897,00). Porém, há um declínio desta disposição nos estratos socioeconômicos 7 
e 8 . O número de respostas "sem opinião formada" sobre esta questão varia muito de estrato para estrato, no entanto, os estratos 6 e 7 apresentam um menor percentual de respostas nesta categoria (Figura 3).

Destaca-se também nos dados obtidos, uma maior disposição em adquirir um produto orgânico com valor agregado nos estratos sociais 6 e 7. Uma possibilidade recomendada nestes casos, conforme a bibliografia consultada, é a utilização da estratégia de marketing centrada no cliente, que visa a atender a determinados "nichos de mercado", tais estratégias envolvendo a segmentação do mercado, com a definição do mercado-alvo, a diferenciação do produto e o posicionamento no mercado. Estas estratégias podem até restringir de certo modo o mercado consumidor em que a empresa irá atuar, porém, por outro lado, as classes socioeconômicas mais elevadas representam uma parcela importante do mercado e exercem o papel de formadoras de opinião na sociedade (MAZZA, 2011; KOTLER; ARMSTRONG, 2007).

A análise da relação entre o grau de escolaridade dos consumidores e a disposição a pagar um acréscimo no preço do ovo orgânico mostra que a indisposição decresce conforme se eleva o grau de escolaridade, talvez pelo fato de os consumidores terem ou buscarem mais informações sobre produtos orgânicos. Em contrapartida, observa-se aumento da disposição a pagar mais conforme se eleva o grau de escolaridade, embora haja um pequeno declínio na população com ensino superior incompleto (Figura 4). 


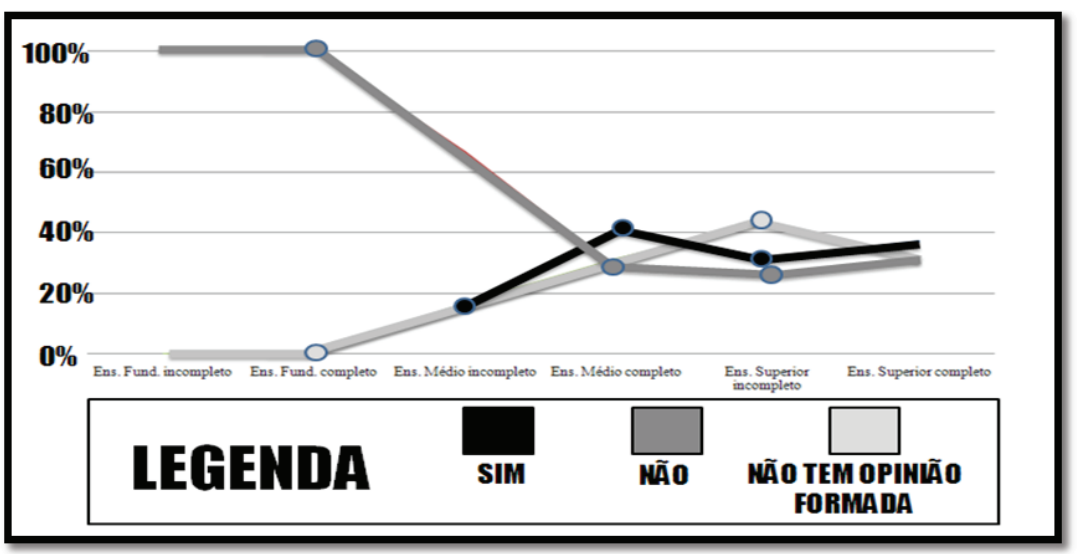

Figura 4 - Disposição a pagar mais pelo produto orgânico conforme a escolaridade

Os cálculos dos coeficientes de correlação de Pearson, considerando as variáveis sexo, idade, escolaridade, estado civil e renda dos participantes da pesquisa, não apontam para uma correlação significativa entre estas variáveis e a disposição dos participantes a pagar mais para consumir ovos orgânicos. Observa-se, inclusive, uma leve correlação negativa para sexo, estado civil e renda (Tabela 1).

Tabela 1 - Correlações de Pearson $(r)$ para a disposição dos consumidores a pagar mais para consumir ovos orgânicos

Correlação de Pearson (r)

\begin{tabular}{ccc}
\hline & Pagaria mais por ovo orgânico? & Desvio Padrão \\
\hline Sexo & $-0,03$ & 0,98 \\
Idade & 0,00 & 10,91 \\
Escolaridade & 0,17 & 1,08 \\
Estado Civil & $-0,04$ & 0,90 \\
Renda & $-0,01$ & 1,56 \\
\hline
\end{tabular}


Os dados resultantes desta primeira etapa da pesquisa indicam um possível desconhecimento dos consumidores sobre o que é o ovo orgânico, seus benefícios, seu sistema de produção e, principalmente, o que o difere dos ditos ovos caipiras. Tal indício será explorado na etapa posterior discutida no tópico seguinte.

\subsection{Motivos pelos quais os consumidores estariam ou não dispostos a pagar mais pelo produto orgânico}

Os resultados do levantamento feito na primeira etapa do estudo indicam que realmente há uma parcela da população (33\% da amostra) que está disposta a pagar mais pelo produto orgânico, entretanto, a maioria dos entrevistados (67\%) ou não está disposta a pagar mais por esse tipo de produto ou não tem uma opinião formada sobre o assunto. As entrevistas qualitativas feitas com alguns respondentes da amostra da primeira etapa, ou seja, a segunda etapa do método, sugerem que o principal motivo para a não disposição a desembolsar maiores valores para consumir produtos orgânicos está na falta de conhecimento dos benefícios que esses produtos trazem para o consumidor e para a sociedade.

Indagações dos pesquisados como "Mas do que se trata um ovo orgânico?”, “Ovo Orgânico é um ovo mais nutritivo?” ou "Qual a diferença entre ovo orgânico e ovo caipira?" mostram claramente que, mesmo entre os que estão dispostos a pagar mais pelo produto orgânico, há falta de informações e de conhecimento sobre o que realmente é o produto, o que ele agrega de valor em relação à qualidade, valor nutricional, saúde, sistema de produção, proteção ao meio ambiente e bem- estar dos animais.

Os entrevistados, que afirmam estar dispostos a pagar mais pelo produto, imaginam que há maior valor agregado ao produto orgânico, porém, não sabem afirmar qual é esse maior valor. "O ovo orgânico é mais saudável porque não é criado à base de hormônios", "Eu estou disposto a pagar mais por um produto verde" são algumas das respostas que evidenciam esse aspecto. Tal fato aponta para a falta de estratégias adequadas de 
divulgação e promoção desses produtos ou para estratégias ineficientes, que não estão mostrando para o consumidor os benefícios do produto e, consequentemente, não estão criando valor.

Outro ponto a ser destacado é a confusão generalizada causada por essa comunicação ineficiente ou inadequada que leva o consumidor a não entender o que é um produto sustentável, um produto orgânico, um produto light ou diet, deixando na verdade esses produtos competindo dentro de um mesmo nicho de mercado, quando, na verdade, são produtos com propostas totalmente distintas, ideia semelhante é compartilhada por Mazza (2011). Entre as respostas dos entrevistados que não estão dispostos a pagar mais pelo produto orgânico, destacam-se: "Não estou disposto a pagar mais por um produto só por ser caipira", "ovo orgânico engorda mais que o ovo normal", "não faço ideia das diferenças entre ovo orgânico e não orgânico, pra mim é tudo igual". Tais respostas evidenciam a discussão sobre a comunicação dos benefícios do produto e sua diferenciação, que, se realmente mostradas para o consumidor, provavelmente criarão maior valor para os produtos e poderão atingir essa demanda reprimida.

Neste sentido, durante as entrevistas, foram apontados pelos autores do estudo os benefícios e as características do produto orgânico em foco, entre as quais: as aves são criadas soltas e alimentadas somente à base de milho, soja e trigo; a alimentação das aves não contém hormônios ou antibióticos e nenhum produto de origem animal; os grãos utilizados são produzidos em terras livres do uso de agrotóxicos, transgênicos, pesticidas e fertilizantes sintéticos, de acordo com a legislação brasileira; há uma série de normas e cuidados animais que asseguram o bem-estar e o tratamento humanitário das aves; todo o processo é certificado e auditado por entidades competentes; a atividade fornece alternativa de sustento para diversos pequenos produtores; entre outros aspectos (FAO; WHO, 2007; MAPA, 2013).

Após essa explicação, todos os respondentes que não estavam dispostos a pagar mais pelo produto orgânico ou não tinham uma opinião formada para decidir pela compra passaram a manifestar disposição a comprar, 
e alguns deles ainda questionaram os entrevistadores sobre como se certificar de que o ovo é orgânico e onde encontrar o produto. Tais comportamentos reforçam a necessidade de melhores estratégias de comunicação e divulgação dos produtos e confirmam a hipótese de que as estratégias de marketing verde podem agregar valor aos produtos orgânicos. Todavia, este consumidor deve estar ciente o que é realmente o produto, seus benefícios e características, para, então, visualizar maior valor no produto orgânico e estar disposto a absorver estes custos envolvidos na produção de um produto diferenciado.

Neste sentido, a terceira etapa da pesquisa analisou uma empresa do setor de produtos orgânicos quanto às suas estratégias de comercialização e possível utilização de estratégias de marketing verde.

4.3. Exemplo de estratégias de marketing verde utilizada na comercialização de produtos orgânicos

A "Produtos Orgânicos LTDA.” é uma empresa que está no mercado há mais de cinco anos, sendo especializada na produção e comercialização de produtos orgânicos, entre os quais o ovo orgânico. O ovo orgânico comercializado pela empresa é certificado pela Organização Internacional Agropecuária e detém o selo Produto Orgânico Brasil, conforme a Lei N ${ }^{\circ}$ 10.831/03, o Decreto $N^{0} 6.323 / 07$ e as instruções normativas pertinentes do MAPA (2013). Atualmente, a empresa comercializa seus produtos com entrega direta ao consumidor e também em feiras livres e lojas especializadas.

De acordo com os dados obtidos por meio da entrevista com o representante da empresa, a "Produtos Orgânicos LTDA." não posiciona necessariamente o seu produto orgânico com maior preço em relação ao produto convencional. Todavia, na tentativa de manter a margem de lucro planejada, a empresa acaba, na maioria das vezes, vendendo seu produto por um preço superior ao praticado no mercado com produtos convencionais (não orgânicos) pela necessidade de absorver os custos de produção que variam durante o ano, segundo o entrevistado. 
Para tanto, foram identificadas, por informações disponibilizadas, algumas estratégias de marketing verde como: (a) exibição dos selos e certificados nas embalagens (verdes) com o objetivo de promover a diferenciação do produto orgânico; (b) nas feiras e lojas especializadas, a empresa divulga os benefícios ligados à sustentabilidade da produção orgânica em stands e gôndolas, onde ficam dispostos os produtos na comercialização; e (c) o portal eletrônico da empresa na internet disponibiliza uma série de informações sobre o processo produtivo mais sustentável, as parcerias com fornecedores da agricultura familiar, receitas saudáveis com a utilização do produto, certificados e diversas outras informações relacionadas aos benefícios "verdes" do produto orgânico.

Todas essas ações ligadas ao marketing verde aplicadas à produção orgânica são necessárias para a criação de maior valor para os produtos e sua diferenciação no mercado. Entretanto, há uma série de outras ações sugeridas pela literatura pertinente ao assunto que podem ser utilizadas no sentido de promover e posicionar melhor o produto orgânico no mercado, como, por exemplo, segmentação do mercado, seleção do público-alvo, diferenciação, posicionamento, exposição continuada, merchandising, venda conceitual (KOTLER; ARMSTRONG, 2007; KOTLER; KELLER, 2006).

Os resultados das três etapas da metodologia utilizada indicam uma carência generalizada de informações consistentes sobre os produtos orgânicos, suas características, benefícios e diferenciações dos produtos convencionais e demais produtos "verdes". Apesar de a empresa investigada adotar estratégias de marketing verde no sentido de posicionar e diferenciar seu produto no mercado, novas ações e investimentos, tanto da empresa focada, como da cadeia produtiva, serão necessários para que os consumidores realmente percebam os atributos "verdes" dos produtos orgânicos e vislumbrem maior valor nesse segmento de produtos. 


\section{Conclusões}

O estudo confirma que as estratégias de marketing verde aplicadas na comercialização de produtos orgânicos realmente criam maior valor na concepção de boa parte dos consumidores, sendo que, uma parcela significativa destes consumidores, se bem informada quanto aos benefícios dos produtos orgânicos, está disposta a pagar mais por eles.

No entanto, apesar de parte dos consumidores estar disposta a pagar mais pelo produto orgânico, boa parte não sabe realmente quais os benefícios e nem o que é o produto, e dos que concordam em pagar mais, poucos afirmam consumir pelo fato de raramente encontrarem tais produtos disponíveis no varejo. Assim, as estratégias de marketing verde para comercialização de produtos orgânicos são de grande valia, porém ainda não estão sendo aplicadas de modo a atingir um número considerável de consumidores e muitas vezes não estão sendo tão efetivas quanto deveriam. Faz-se necessário divulgar melhor o que é o produto orgânico e seus benefícios, para assim aproximá-lo do consumidor.

Evidentemente, por se tratar de uma investigação de uma temática complexa a partir de uma abordagem distinta, é natural que existam limitações relacionadas à amostra e ao produto escolhido para a investigação. Todavia, ressalta-se a necessidade da utilização de diferentes metodologias e abordagens, em diferentes populações, com diferentes produtos orgânicos e múltiplas estratégias de marketing verde para o melhor aprofundamento do tema e confirmação das evidências apresentadas. 


\section{Referências}

AGRAWAL, Akash Deepak. GREEN MARKETING: SUSTAINABLE MARKETING STRATEGY. Indira Management Review, p. 17, 2013.

BALDWIN, Cheryl J. (Ed.). Sustainability in the food industry. Wiley. com, 2012.

BLACKWELL, R. D.; MINIARD, P. W.; ENGEL, J. F. Comportamento do consumidor. São Paulo: Pioneira Thomson Learning, 2005.

CRONIN JR, J. Joseph et al. Green marketing strategies: an examination of stakeholders and the opportunities they present. Journal of the Academy of Marketing Science, v. 39, n. 1, p. 158-174, 2011.

DARNALL, Nicole; PONTING, Cerys; VAZQUEZ-BRUST, Diego A. Why consumers buy green. In: Green growth: Managing the transition to a sustainable economy. Springer Netherlands, 2012. p. 287-308.

FOOD AND AGRICULTURE ORGANIZATION OF THE UNITED NATIONS - FAO; WORLD HEALTH ORGANIZATION. Organically Produced Foods. Rome: Codex AlimentariusComission, $3^{\text {a }}$ ed., 2007.

GARSON, G. David. Statnotes: Topics in Multivariate Analysis, 2009. Disponível em: http://faculty.chass.ncsu.edu/garson/PA765/statnote.htm

GINSBERG, Jill Meredith; BLOOM, Paul N. Choosing the right green marketing strategy. MIT Sloan Management Review, v. 46, n. 1, p. 79-84, 2004.

HUGHNER, Renee Shaw et al. Who are organic food consumers? A compilation and review of why people purchase organic food. Journal of consumer behaviour, v. 6, n. 2-3, p. 94-110, 2007.

JANSSON, Johan; MARELL, Agneta; NORDLUND, Annika. Green consumer behavior: determinants of curtailment and eco-innovation 
adoption. Journal of Consumer Marketing, v. 27, n. 4, p. 358-370, 2010.

KAMAKURA, Wagner A.; MAZZON, José Afonso. Estratificação Socioeconômica e Consumo no Brasil. São Paulo: Blucher, 2013.

KOTLER, Philip; ARMSTRONG, Gary. Princípios de Marketing. 12. ed. São Paulo: Pearson Prentice Hall, 2007.

KOTLER, Philip; KARTAJAYA, Hermawan; SETIAWAN, Iwan. Marketing 3.0: from products to customers to the human spirit. John Wiley \& Sons, 2010.

KOTLER, Philip; KELLER, Kevin L. Administração de Marketing. 12. ed. São Paulo: Prentice Hall, 2006.

LOPES, Evandro Luiz; DA SILVA, Dirceu. Modelos Integrativos do Comportamento do Consumidor: Uma Revisão Teórica. Brazilian Journal of Marketing, v. 10, n. 3, p. 03-23, 2012.

MALHOTRA, N. K. Pesquisa de marketing: uma orientação aplicada. 4. ed. Porto Alegre: Bookman, 2006.

MATHUR, Lynette Knowles; MATHUR, Ike. An analysis of the wealth effects of green marketing strategies. Journalof Business Research, v. 50, n. 2, p. 193-200, 2000.

MAZZA, L. Mercados verdes: conceitos e casos In: NETO, J. A. (Org.). Sustentabilidade \& Produção. São Paulo: Atlas, p. 187-230, 2011.

MINISTÉRIO DAAGRICULTURA, PECUÁRIAEABASTECIMENTO - MAPA. Desenvolvimento Sustentável - Orgânicos. Disponível em: <http://www.agricultura.gov.br/desenvolvimento-sustentavel/ organicos>. Acesso em: 2 de nov. 2013. 
MOWEN, John C.; MINOR, Michael S. Comportamento do consumidor. Prentice-hall, 2003.

NEVES, Marcos F. et al. Comportamento do consumidor e novo consumidor de alimentos. Marketing e estratégia em agronegócios e alimentos. São Paulo: Atlas, p. 73-87, 2007.

NEVES, Marcos Fava. The future of food business: the facts, the impacts and the acts. World Scientific, 2011.

OTTMAN, Jacquelyn A.; STAFFORD, Edwin R.; HARTMAN, Cathy L. Avoiding green marketing myopia: ways to improve consumer appeal for environmentally preferable products. Environment: Science and Policy for Sustainable Development, v. 48, n. 5, p. 22-36, 2006.

OTTMAN, Jacquelyn. Green Marketing| Sustainability Marketing, The New Rules of Green Marketing Book| J. Ottman Consulting. 2013.

PEATTIE, Ken; CRANE, Andrew. Green marketing: legend, myth, farce or prophesy? Qualitative Market Research: An International Journal, v. 8, n. 4, p. 357-370, 2005.

SHEPHERD, Richard; MAGNUSSON, Maria; SJÖDÉN, Per-Olow. Determinants of consumer behavior related to organic foods. AMBIO: A Journal of the Human Environment, v. 34, n. 4, p. 352-359, 2005.

SMITH, T. A.; LIN, B-H; HUANG, C. L. Growth and development in the U.S. retail organic food sector. Sustainability, v. 1, p. 573-591, sept., 2009.

TARKIAINEN, A.; SUNDQVIST, S. Subjective norms, attitudes and intentions of Finnish consumers in buying organic food. British Food Journal, Bingley, v. 107, n. 11, p. 808-22, 2005.

VERAIN, Muriel CD et al. Segments of sustainable food consumers: a literature review. International Journal of Consumer Studies, v. 36, n. 2, p. 123-132, 2012. 
WINTER, Carl K.; DAVIS, Sarah F. Organic foods. Journal of Food Science, v. 71, n. 9, p. R117-R124, 2006.

WOOLVERTON, Andrea; DIMITRI, Carolyn. Green marketing: Are environmental and social objectives compatible with profit maximization?.Renewable agriculture and food systems, v. $25, n$. 2 , p. $90,2010$.

YOUNG, William et al. Sustainable consumption: green consumer behaviour when purchasing products. Sustainable Development, v. 18, n. 1, p. 20-31, 2010. 
REVISTA DE ECONOMIA E AGRONEGÓCIO, VOL.11, $N^{\circ} 2$ 